\title{
Biodegradable micelles enhance the antiglioma activity of curcumin in vitro and in vivo
}

\author{
This article was published in the following Dove Press journal: \\ International Journal of Nanomedicine \\ 9 June 2016 \\ Number of times this article has been viewed
}

\author{
Songping Zheng ${ }^{1, *}$ \\ Xiang Gao ${ }^{1,2, *}$ \\ Xiaoxiao Liu' \\ Ting Yu' \\ Tianying Zheng' \\ YiWang' \\ Chao You' \\ 'Department of Neurosurgery, \\ West China Hospital, West China \\ Medical School, Sichuan University, \\ Chengdu, People's Republic of China; \\ ${ }^{2}$ Department of Pharmacology, Yale \\ School of Medicine, Yale University, \\ New Haven, CT, USA \\ *These authors contributed equally \\ to this work
}

\begin{abstract}
Curcumin (Cur), a natural polyphenol of Curcuma longa, has been recently reported to possess antitumor activities. However, due to its poor aqueous solubility and low biological availability, the clinical application of Cur is quite limited. The encapsulation of hydrophobic drugs into nanoparticles is an effective way to improve their pharmaceutical activities. In this research, nanomicelles loaded with Cur were formulated by a self-assembly method with biodegradable monomethoxy poly(ethylene glycol)-poly(lactide) copolymers (MPEG-PLAs). After encapsulation, the cellular uptake was increased and Cur could be released from MPEG-PLA micelles in a sustained manner. The Cur-loaded MPEG-PLA micelles (Cur/MPEG-PLA micelles) exhibited an enhanced toxicity on C6 and U251 glioma cells and induced more apoptosis on C6 glioma cells compared with free Cur. Moreover, the therapy efficiency of Cur/MPEG-PLA micelles was evaluated at length on a nude mouse model bearing glioma. The Cur/MPEG-PLA micelles were more effective on suppressing tumor growth compared with free Cur, which indicated that Cur/MPEGPLA micelles improved the antiglioma activity of Cur in vivo. The results of immunohistochemical and immunofluorescent analysis indicated that the induction of apoptosis, antiangiogenesis, and inhibition of cell proliferation may contribute to the improvement in antiglioma effects. Our data suggested that Cur/MPEG-PLA may have potential clinic applications in glioma therapy.

Keywords: curcumin, glioma, cell apoptosis, cell proliferation, angiogenesis
\end{abstract}

\section{Introduction}

An increasing number of patients have been diagnosed with glioma in USA over the past decades. ${ }^{1}$ More than a half of them are glioblastoma multiforme, which is one of the most malignant tumors of the brain characterized by high proliferation, migration, and aggression. Although major improvements have been made in standardized treatment, containing surgical resection, radiotherapy, and chemotherapy, the overall prognosis of glioblastoma multiforme is still very poor, with the median survival of $\sim 1$ year after diagnosis. ${ }^{2-4}$ Chemotherapy should be the most curative method since surgery and radiation are restricted by permeation of tumor cells into normal brain tissues. However, the effectiveness of conventional chemotherapy is severely hindered since chemotherapeutic drugs are often eliminated in circulation and hard to reach a high local drug concentration in the tumor site. Moreover, the overexpression of multidrug resistance proteins by tumor cells causes efflux of various chemotherapeutic drugs. ${ }^{5-7}$ Therefore, new chemotherapeutic agents are sorely needed.

Curcumin (Cur), a natural polyphenol isolated from the rhizome of the plant Curcuma longa, is regarded to be nontoxic to humans since being part of the daily food of millions of Indians. It has been reported to possess anticancer property through various mechanisms, including cell cycle inhibition (suppressing cyclin D and inducing p21), differentiation induction (promoting autophagy), apoptosis promotion (activating
Correspondence: Chao You Department of Neurosurgery, West China Hospital, West China Medical School, Sichuan University, No 37, Guoxue Alley, Chengdu 61004I, People's Republic of China

Tel +862885422136

Fax +8628 85502796

Email chaoyouyouchao@163.com
International Journal of Nanomedicine 2016: I | 2721-2736

(c) (1) (8) ( 2016 hheng et al. This work is published and licensed by Dove Medical Press Limited. The full terms of this license are avalable at https://www.dovepress.com/terms.php

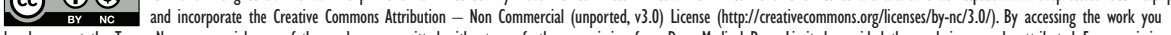
hereby accept the Terms. Non-commercial uses of the work are permitted without any further permission from Dove Medical Press Limited, provided the work is properly attributed. For permision for commercial use of this work, please see paragraphs 4.2 and 5 of our Terms (https://www.dovepress.com/terms.php).

2721
Dovepress

http://dx.doi.org/10.2147/IJN.SI 02450 
caspase-3 and reducing bcl-xl), and anticancer drug resistance (targeting cancer stem cells). ${ }^{8-11}$ More significantly, studies showed that Cur selectively targeted tumor cells, leaving normal neural cells intact. ${ }^{12,13}$ However, due to its poor aqueous solubility, fast metabolism, and low biological availability, the clinical application of Cur is quite limited. Scientists have been developing different drug delivery systems that are expected to resolve the hydrophobic property, prolong the circulation time in blood, and increase the release to the targeted tissue, such as cyclodextrin complex, solid dispersion, phospholipid complex, and others. ${ }^{14-16}$ But there exist different problems in practice, such as highly unstable, less effective, or difficult for manufacturing.

Nanomedicine, which is an important branch of nanotechnology, has been rapidly developing in recent years. It is expected to play a vital role in early diagnosis and accurate treatment of diseases at molecular level. In the field of anticancer research, nanodelivery system has attracted much attention. Through the combination of drug and carrier, hydrophobic agents can be water soluble. Pharmacokinetics and biodistribution of drug could also be altered, so as to improve the bioavailability and specificity. ${ }^{17-19}$ Nanocarriers are mainly composed of silica, gold, iron oxides, liposomes, and polymeric nanocarriers, such as polyelectrolyte complexes, micelles, and hydrogels. Among them, biodegradable polymeric micelles are an attractive delivery system with nanoscale hydrophilic shell and hydrophobic core binding agents. The drug is combined with polymeric micelles through dissolution or by biodegradable chemical bond. The encapsulation of drug in the biodegradable polymeric micelles enables prolonged circulation time in blood, as well as preferred storage and effective control of drug release in the desired location with low toxicity. ${ }^{20-23}$

In this study, in order to improve the antiglioma efficiency, Cur-loaded monomethoxy poly(ethylene glycol)poly(lactide) copolymers (MPEG-PLAs) were formulated by our group. We planned to explore the efficiency of these Cur/MPEG-PLA micelles at a cellular level by investigating the drug uptake, apoptosis, and cytotoxicity to tumor cells in vitro. More importantly, the subcutaneous tumor model in nude mice was used to evaluate the potential of this new delivery system to treat glioma in vivo.

\section{Materials and methods \\ Materials}

Dulbecco's Modified Eagle's Medium and fetal bovine serum (FBS) were obtained from Thermo Fisher Scientific (Waltham, MA, USA). Cur and 3-(4,5-dimethylthiazol-2-yl)-2,5-diphenyl tetrazolium bromide (MTT) were purchased from SigmaAldrich Co. (St Louis, MO, USA). Methanol and acetic acid (high-performance liquid chromatography [HPLC] grade) were purchased from Thermo Fisher Scientific. Dimethyl sulfoxide and acetone were purchased from KeLong Chemicals (Chengdu, People's Republic of China).

MPEG(2000)-PLA(2000) diblock copolymer with a designed molecular weight of 4,000 Da was synthesized by ring opening of L-lactide, initiated by MPEG. MPEG (5.0 g) was melted in a $50 \mathrm{~mL}$ flask following the addition of anhydrous L-lactide $(5.0 \mathrm{~g})$ and $\mathrm{Sn}(\mathrm{Oct})_{2}(1 \mathrm{~mL})$ under nitrogen. The mixture reactant was maintained at $125^{\circ} \mathrm{C}$ for 24 hours. The crude product was dissolved in tetrahydrofuran and then purified by precipitation in ice-cooled diethyl ether followed by filtration. This process was performed in triplicate, and the resultant product was vacuum dried at ambient temperature. The number average molecular weight (Mn) of MPEG-PLA copolymer was 4,010 Da (data not shown). The MPEG (molecular weight $=2,000 \mathrm{Da}$ ) (Sigma-Aldrich Co.) was dried in a one-necked flask under vacuum and magnetically stirred at $105^{\circ} \mathrm{C}$ for 90 minutes before use.

The C6 and U251 cells (obtained from American Type Culture Collection [ATCC], Manassas, VA, USA) were cultured in Dulbecco's Modified Eagle's Medium supplemented with $10 \%$ heat-inactivated FBS and $100 \mu \mathrm{g} / \mathrm{mL}$ amikacin and were maintained in humidified incubator at $37^{\circ} \mathrm{C}$ in $5 \%$ $\mathrm{CO}_{2}$-containing atmosphere. Sichuan University waived the requirement to obtain ethical approval for using the rat C6 glioma and human U251 glioma commercialized cell lines.

Male Sprague Dawley rats and female nude BALB/c mice (6-8 weeks old) were used for in vivo pharmacokinetic and antitumor test studies. The animals were purchased from the Laboratory Animal Center of Sichuan University, and were separately housed according to their sex at controlled temperature of $20^{\circ} \mathrm{C}-22^{\circ} \mathrm{C}$, relative humidity of $50 \%-60 \%$, and 12-hours light-dark cycles. Animals were provided with standard laboratory chow and tap water ad libitum. All the animals would be in quarantine for a week before treatment. All animal procedures were performed according to the protocol approved by the Institutional Animal Care and Treatment Committee of Sichuan University (Chengdu, People's Republic of China). All mice were treated humanely throughout the experimental period.

\section{Preparation of Cur/MPEG-PLA micelles}

Cur/MPEG-PLA micelles were prepared by a self-assembly method. Cur (10 mg) and MPEG-PLA (90 mg) were codissolved in $5 \mathrm{~mL}$ acetone under stirring. The abovementioned 
mixture was evaporated in rotary evaporator at $55^{\circ} \mathrm{C}$ using negative pressure. Subsequently, the resultant co-evaporant was dissolved in water. The solution was filtered by a syringe filter $(0.22 \mu \mathrm{m})$ and then lyophilized and stored at $4^{\circ} \mathrm{C}$ before use.

\section{Characteristics of Cur/MPEG-PLA micelles}

Drug loading (DL) and encapsulation efficiency (EE) of Cur/MPEG-PLA micelles were determined as follows. Briefly, $10 \mathrm{mg}$ of lyophilized Cur/MPEG-PLA micelles was dissolved in $0.1 \mathrm{~mL}$ of acetonitrile. The amount of Cur in the solution was determined by HPLC (LC-20AD; Shimadzu Corporation, Tokyo, Japan). The DL and EE of Cur/MPEG-PLA micelles were calculated according to the following equations:

$$
\begin{gathered}
\text { DL }=\frac{\text { Drug }}{\text { Polymer }+ \text { Drug }} \times 100 \% \\
\mathrm{EE}=\frac{\text { Experimental drug loading }}{\text { Theoretical drug loading }} \times 100 \%
\end{gathered}
$$

The particle size and zeta potential of Cur/MPEG-PLA micelles were measured by dynamic light scattering. The $100 \mu \mathrm{L}$ micelles were dissolved in $2 \mathrm{~mL}$ of distilled water (micelles concentration: $1 \mathrm{mg} / \mathrm{mL}$ ), then the test was performed in triplicate.

The examination of transmission electron microscopy (TEM) samples followed the following procedures. In brief, the Cur/MPEG-PLA micelles solution was placed dropwise onto a copper grid. Approximately 15 minutes after nanoparticle deposition, the grid was tapped with filter paper to remove excess water and stained using a solution of phosphotungsten acid $(2 \%, \mathrm{w} / \mathrm{v})$ for 20 minutes. After the stained sample was allowed to air dry, TEM samples were obtained. A photomicrogram of Cur/MPEG-PLA micelles was obtained by using a transmission electron microscope (high-resolution transmission electron microscopy) (Tecnai G2 F20 S-TWIN).

Release of Cur from the Cur/MPEG-PLA micelles was performed by the dialysis membrane method. First, $1 \mathrm{~mL}$ of Cur/MPEG-PLA micelles solution (equivalent to $1 \mathrm{mg}$ of Cur) was transferred in dialysis bags (Sigma-Aldrich Co.) with a molecular cutoff $3.5 \mathrm{kDa}$. The bags were suspended in $200 \mathrm{~mL}$ of phosphate-buffered saline (PBS) (pH 7.4) with $0.5 \%$ Tween 80 at $37^{\circ} \mathrm{C}$ in a shaking water bath at $100 \mathrm{rpm}$. At selected time intervals, $200 \mu \mathrm{L}$ of normal saline (NS) sample was collected and replaced by an equal volume of fresh medium. The Cur content of PBS with Tween 20 was analyzed by an HPLC system.

\section{Pharmacokinetic}

Male Sprague Dawley rats (200 \pm 10 g body weight) were randomly assigned to two groups for pharmacokinetic investigation. Groups 1 and 2 received an intravenous (iv) injection of free Cur and Cur/MPEG-PLA micelles through the tail vein, respectively, at an equivalent dose of $60 \mathrm{mg} / \mathrm{kg}$ Cur versus the body weight. At time points of 0 (pre-dose), 15 minutes, 30 minutes, 1 hour, 2 hours, 4 hours, 8 hours, 12 hours, and 24 hours post-injection, $0.5 \mathrm{~mL}$ of blood was collected in heparinized polyethylene tubes via carotid artery and centrifuged at $1,000 \times g$ for 10 minutes to obtain plasma. The plasma was separated and extracted with ethyl acetate, and supernatant fluid was collected and evaporated to dryness. The dry residues were dissolved in methanol for HPLC analysis.

\section{MTT test}

The MTT assay was applied to determine the cell proliferation. The C6 and U251 cells were planted in 96-well plates containing FBS $\left(3 \times 10^{3}\right.$ cells/well for 48 -hour incubation and $5 \times 10^{3}$ cells/well for 24 -hour incubation). Then, the cells were treated with free Cur or Cur/MPEG-PLA micelles at different concentrations $(50 \mu \mathrm{g} / \mathrm{mL}, 25 \mu \mathrm{g} / \mathrm{mL}, 12.5 \mu \mathrm{g} / \mathrm{mL}$, $6.25 \mu \mathrm{g} / \mathrm{mL}, 3.125 \mu \mathrm{g} / \mathrm{mL}, 1.563 \mu \mathrm{g} / \mathrm{mL}$, and $0.753 \mu \mathrm{g} / \mathrm{mL}$ ). After incubation for 24 hours or 48 hours, $5 \mathrm{mg} / \mathrm{mL}$ of MTT solution was added. The cells were then incubated for 3 hours and combined with dimethyl sulfoxide. Formazan generated by cellular dehydrogenase was measured by IMARK microplate reader (Multiskan; Thermo Fisher Scientific, USA) at $570 \mathrm{~nm}$ of absorbance.

\section{Apoptosis study}

The apoptosis of C6 cells was assayed with flow cytometry (FCM, BD FACSCalibur). Briefly, C6 cells were seeded into six-well plates $\left(3 \times 10^{5}\right.$ cells/well $)$ and allowed to attach overnight. Then the cells were treated with free Cur or Cur/ MPEG-PLA micelles at different concentrations for 24 hours $(12.5 \mu \mathrm{g} / \mathrm{mL}, 6.25 \mu \mathrm{g} / \mathrm{mL}$, and $3.125 \mu \mathrm{g} / \mathrm{mL})$. Cells treated only with micelles were used as blank control. In the next step, the cells were harvested and combined with $5 \mu \mathrm{L}$ Annexin V-fluorescein isothiocyanate (FITC) and $5 \mu \mathrm{L}$ propidium iodide (PI) (Annexin V-FITC/PI Apoptosis Detection Kit). The stained cells were then analyzed with FCM.

\section{Cellular uptake}

Cellular uptake of free Cur and Cur/MPEG-PLA micelles was monitored by confocal microscopy and FCM. The C6 and U251 cells were grown in six-well culture plates 
$\left(3 \times 10^{5}\right.$ cells/well) and incubated overnight at $37^{\circ} \mathrm{C}$. Subsequently, cells were treated with nonencapsulated Cur or Cur/ MPEG-PLA micelles at various concentrations, respectively (6.25 $\mu \mathrm{g} / \mathrm{mL}$ or $3.125 \mu \mathrm{g} / \mathrm{mL})$. Cells treated with empty micelles (EM) served as control in the experiment. After 4 hours, the cells were washed three times with PBS to prevent contamination. Subsequently, the cells were viewed and photographed under a fluorescence microscopy. FCM was applied for quantification of intracellular Cur. After centrifugation at 1,000 rpm, cells were harvested and analyzed by FCM equipped with a $488 \mathrm{~nm}$ argon laser. The fluorescence emission at FL-1 from 10,000 cells was measured to compare the difference in cellular uptake between cells treated with free Cur and cells treated with Cur/MPEG-PLA micelles.

\section{Antiglioma cancer in vivo}

For in vivo implantation, C6 cells were injected subcutaneously at $1 \times 10^{7}$ cells in $0.1 \mathrm{~mL}$ in the right flank of the mice. When the tumor volume reached $\sim 100 \mathrm{~mm}^{3}$, the mice were randomized into four groups (five mice each group) and treated with one of the following regimens: 1) NS, 2) EM, 3) free Cur (F-Cur, Cur: 50 mg/kg), and 4) Cur/MPEG-PLA micelles (Cur-M, Cur: $50 \mathrm{mg} / \mathrm{kg}$ ). The tumor diameters were measured every other day with a vernier caliper in two dimensions. Individual tumor volume $(V)$ was calculated using the formula: $V=\left(L \times W^{2}\right) \times 0.52$, wherein length $(L)$ is the longest diameter and width $(W)$ is the shortest diameter perpendicular to length. In addition, for safety evaluation of the control and Cur formulations, the body weight of each mouse was determined every alternate day. At the end of the experiment, the animals were sacrificed by cervical dislocation, and the tumor mass was harvested and weighed.

\section{Tunnel assay}

Tumors were first dunked in PBS with 4\% paraformaldehyde for at least 24 hours, then in 70\% ethanol overnight, and finally embedded in paraffin. The 3-5 $\mu \mathrm{m}$ sections were cut and mounted. A terminal deoxynucleotidyl transferasemediated dUTP nick-end labeling (TUNEL) kit (Promega Corporation, Fitchburg, WI, USA) was applied to analyze apoptotic cells within C6 tumors. The samples were detected with fluorescence microscope $(\times 400)$ according to the manufacturer's protocol.

\section{Immunohistochemical determination of $\mathrm{Ki}-67$ and CD3 I}

Antiproliferation and antiangiogenic effects of Cur/MPEGPLA micelles were measured by immunochemistry with antibody Ki67 and CD31. Briefly, the tumor tissue frozen sections were fixed in acetone, washed with PBS, and stained with rabbit antirat Ki67 polyclonal antibody (1:50; BD Pharmingen ${ }^{\mathrm{TM}}$; BD Biosciences, San Jose, CA, USA) and rabbit antimouse CD31 (1:50; Abcam, Cambridge, UK). Then, it was washed twice with PBS, and stained with secondary antibody conjugating FITC or Rhodamine (Abcam). The positive cells were observed under microscope, and the number of capillaries per high-power field was manually counted.

\section{Statistical analyses}

The statistical analysis software SPSS15.0 for Windows (SPSS Inc., Chicago, IL, USA) was used. The results are recorded as mean \pm standard deviation (SD). Analysis of variance was used for multiple group comparisons. $P<0.05$ was considered statistically significant.

\section{Results}

In this study, through the application of nanodelivery system, an aqueous formulation Cur/MPEG-PLA was obtained, and the anticancer activity and mechanism of this formation on glioma were explored in vitro and in vivo.

\section{Preparation and characterization of the Cur/MPEG-PLA micelles}

A highly soluble formation of Cur based on MPEG-PLA was developed by a single step of solvent evaporation method as previously reported. ${ }^{23}$ Cur and MPEG-PLA were codissolved in acetone, evaporated in rotary evaporator, and then combined with NS solution. During this process, Cur and MPEG-PLA self-assembled into Cur/MPEG-PLA micelles, which encapsulated Cur in the core part, with a hydrophilic shell as shown in Figure 1.

The developed Cur/MPEG-PLA micelles were further characterized with respect to particle size, polydispersity

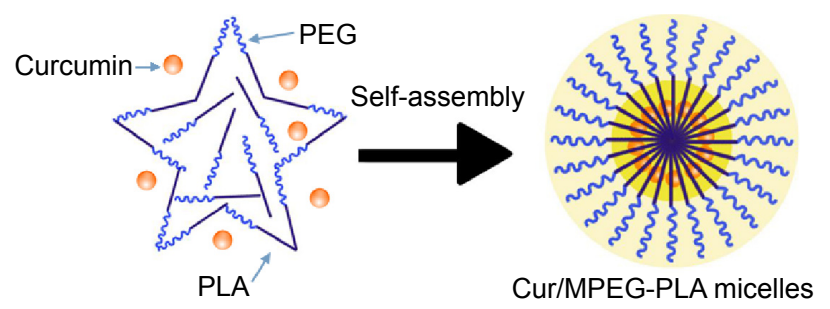

Figure I Preparation of Cur/MPEG-PLA micelles.

Notes: The Cur/MPEG-PLA was prepared by a solvent evaporation method. The MPEG-PLA and curcumin with different proportions were codissolved in acetone. Then through the steps of evaporation and hydration, MPEG-PLA and curcumin self-assembled into Cur/MPEG-PLA micelles.

Abbreviations: Cur, curcumin; MPEG-PLA, monomethoxy poly(ethylene glycol)poly(lactide) copolymer; PEG, poly(ethylene glycol). 
index, zeta potential, and appearance features. In Figure 2A, the size distribution spectrum showed that the Cur/MPEGPLA micelles were monodispersed and had a very narrow particle size distribution (polydispersity index $=0.12 \pm 0.03$ ). These Cur/MPEG-PLA micelles showed an average diameter of $\sim 33 \pm 2.3 \mathrm{~nm}$ in aqueous phase and had the DL of $9.85 \% \pm 0.03 \%$ and EE of $98.5 \% \pm 0.03 \%$. According to Figure 2B, the zeta potential of Cur/MPEG-PLA micelles was $-3.3 \pm 0.3 \mathrm{mV}$. Furthermore, TEM was applied to observe the morphological characteristics of these nanoparticles. Spherical Cur/MPEG-PLA micelles were measured $\sim 23 \mathrm{~nm}$ in drying phase under electron microscope (Figure 2C). Since the structure of these amphiphilic particles was usually loose in solution, the size measured by dynamic light scattering was always a little larger than that measured by TEM.
As shown in Figure 2D, free Cur and Cur/MPEG-PLA micelles showed different dissolution behaviors in NS solution. Compared with free Cur, which formed a cloudy orange suspension (Figure 2Db), the Cur/MPEG-PLA micelle solution was transparent and clear, indicating a complete dispersibility in aqueous solution.

The in vitro release results showed that the Cur can be released slowly from Cur/MPEG-PLA micelles, and the free Cur was released very quickly (Figure $3 \mathrm{~A}$ ). The cumulative percentage release demonstrated that the amount of drug released from nanomicelles was gradually increased over time, and after 120 hours, there was an increase of $>40 \%$. The free Cur exhibited a high level (40\%) at 2 hours. This indicated that Cur could be released from Cur/MPEG-PLA micelles.
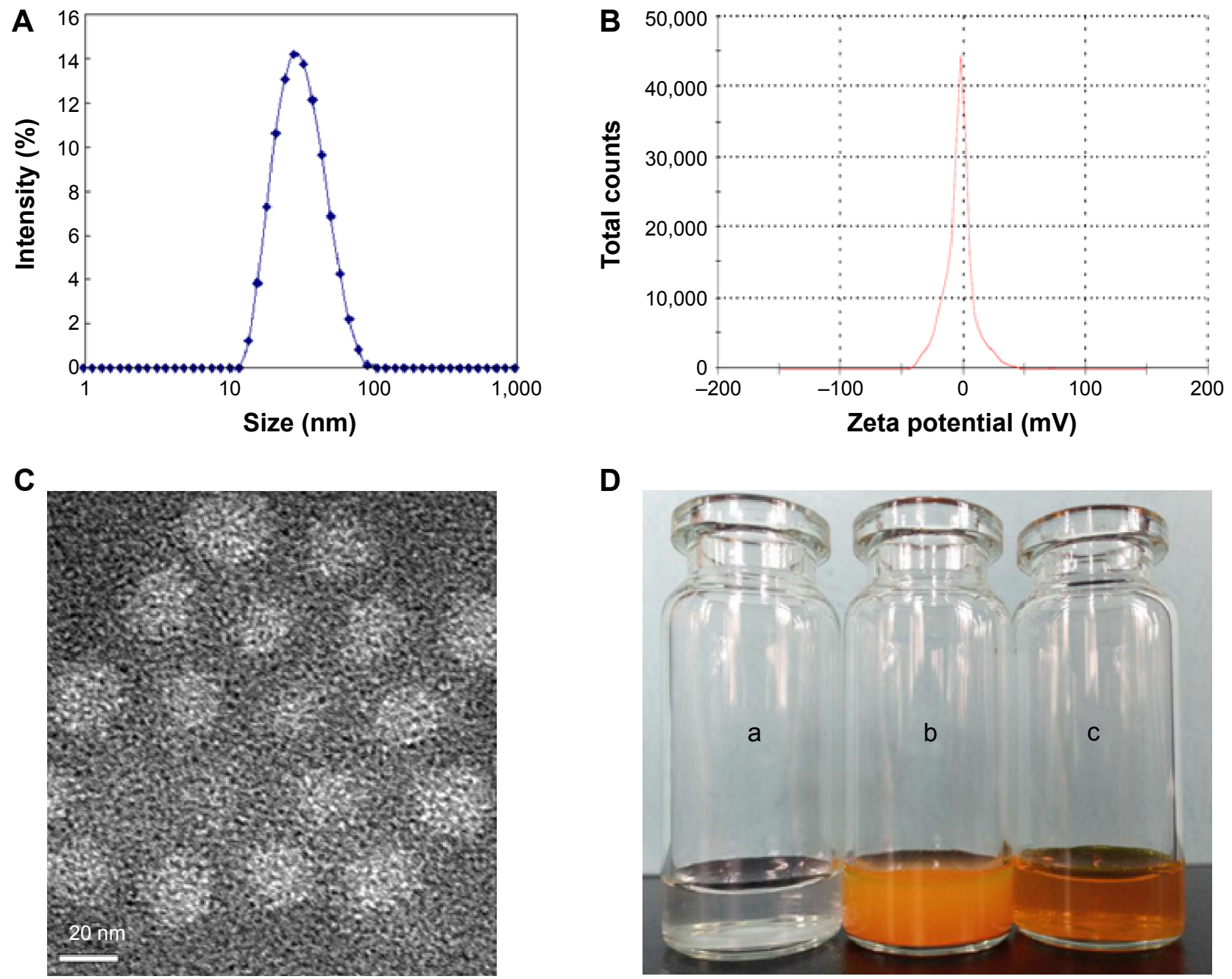

Figure 2 Characterization of Cur/MPEG-PLA micelles.

Notes: (A) Size distribution spectrum of Cur/MPEG-PLA micelles. (B) Zeta potential spectrum of Cur/MPEG-PLA micelles. (C) Transmission electron micrograph of Cur/ MPEG-PLA micelles (bar $20 \mathrm{~nm}$ ). (D) The combination of curcumin and MPEG-PLA modifies the physical property of curcumin, making it easily soluble in aqueous media. (a) Normal saline solution, (b) curcumin suspension, and (c) Cur/MPEG-PLA micelles solution.

Abbreviations: Cur, curcumin; MPEG-PLA, monomethoxy poly(ethylene glycol)-poly(lactide) copolymer. 

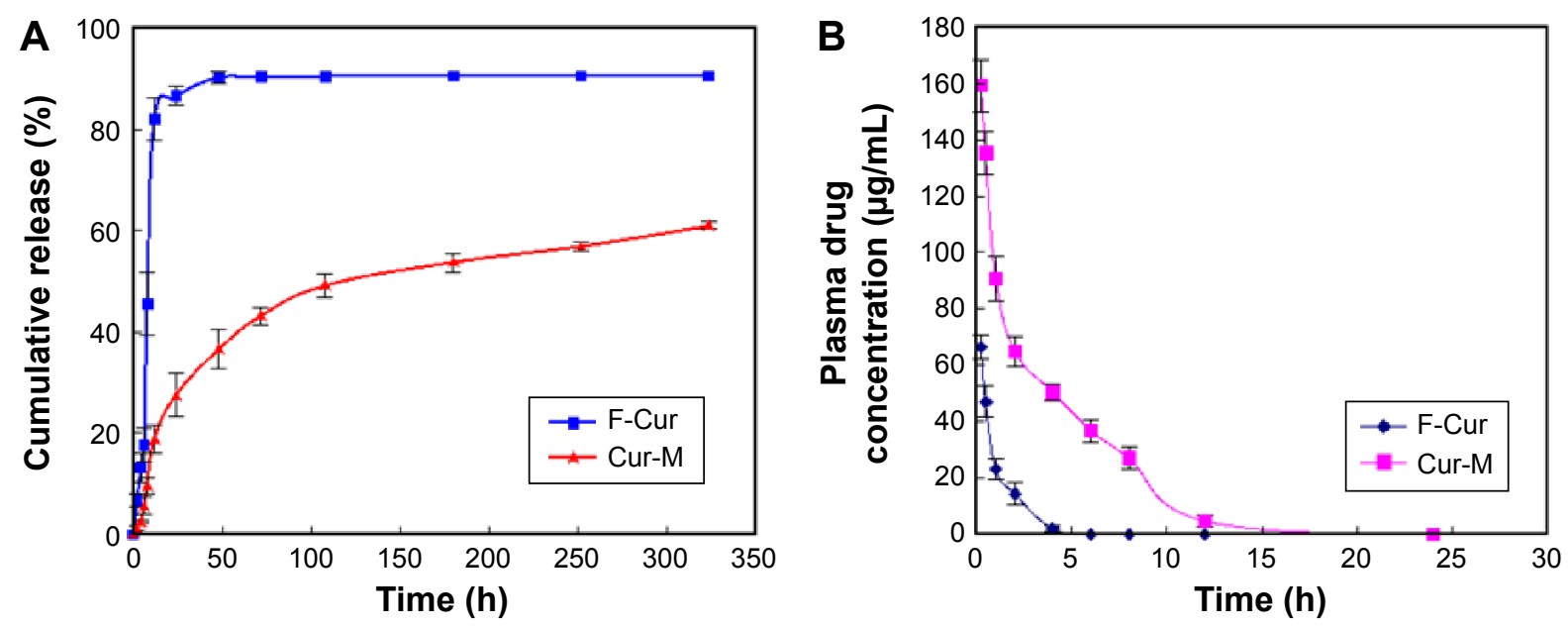

Figure 3 Drug release in vitro and pharmacokinetic studies.

Notes: (A) In vitro release study and (B) in vivo pharmacokinetics assay of free curcumin and Cur/MPEG-PLA micelles.

Abbreviations: Cur, curcumin; MPEG-PLA, monomethoxy poly(ethylene glycol)-poly(lactide) copolymer; F-Cur, free curcumin; Cur-M, Cur/MPEG-PLA micelles; h, hours.

To assess whether the micelles improve bioavailability of poorly water soluble drugs, the mean plasma concentrationtime profiles of Cur after iv administration of free and formulated drug are presented in Figure 3B. Free Cur was rapidly cleared, and the plasma level of Cur was $<2.1 \mu \mathrm{g} / \mathrm{mL}$ of the injected dose within 5 hours of injection. Compared with free drug, Cur concentration in plasma was $\sim 20$-fold higher for Cur/MPEG-PLA micelles at 6 hours after drug injection. The difference was most evident at time points beyond 6 hours (Figure 3B). The results demonstrate that MPEG-PLA-encapsulated Cur reduced drug elimination.

\section{Cur/MPEG-PLA micelles enhance antiglioma cancer activity in vitro}

The anticancer activity of free Cur and Cur/MPEG-PLA micelles was studied in vitro. The MTT assay was applied to investigate the cycotoxicity on two glioma cell lines (C6 and U251). As shown in Figure 4, both free Cur and Cur/MPEGPLA micelles have time- and dose-dependent inhibitive effects on cell viability of C6 and U251 cells. Compared with the 24-hour group, the cell viability of 48-hour group decreases more significantly at the same drug concentration. Meanwhile, the half maximal inhibitory concentration $\left(\mathrm{IC}_{50}\right)$ of Cur/MPEG-PLA micelles was slightly lower than that of free Cur, indicating that MPEG-PLA micelles improved the cytotoxicity of Cur to glioma cells.

The $\mathrm{IC}_{50}$ of free Cur on U251 at 24 hours and 48 hours was $43.37 \mu \mathrm{g} / \mathrm{mL}$ and $10.38 \mu \mathrm{g} / \mathrm{mL}$, respectively, which was higher than that of Cur nanomicelles ( 24 hours: $29.02 \mu \mathrm{g} / \mathrm{mL}$; 48 hours: $6.82 \mu \mathrm{g} / \mathrm{mL}$ ). And $\mathrm{IC}_{50}$ of free Cur on C6 at 24 hours and 48 hours was $4.74 \mu \mathrm{g} / \mathrm{mL}$ and $1.97 \mu \mathrm{g} / \mathrm{mL}$, respectively, which was higher than that of Cur nanomicelles
(24 hours: $4.38 \mu \mathrm{g} / \mathrm{mL}$; 48 hours: $1.57 \mu \mathrm{g} / \mathrm{mL}$ ). These results indicated that the encapsulated Cur by MPEG-PLA could enhance the cytotoxic activity of Cur.

In addition, the intracellular uptake of free Cur and Cur/MPEG-PLA micelles was measured to explore the mechanism of increased toxicity and apoptosis effect. The inset in Figure 5 shows that in the Cur/MPEG-PLA micelle group, a very bright, greenish fluorescence was observed in $\mathrm{C} 6$ cells after 4-hour incubation, indicating an enhanced drug accumulation. In comparison, no fluorescence was found in the group treated with EM, and a weak fluorescence was observed in a few glioma cells in the free Cur group. Moreover, this result was consistent with that obtained by FCM. As shown in Figure 6, the fluorescence intensities in the two glioma cell lines (C6 and U251) treated with Cur/MPEG-PLA micelles at different drug concentrations $(3.125 \mu \mathrm{g} / \mathrm{mL}$ and $6.25 \mu \mathrm{g} / \mathrm{mL})$ were both significantly higher than the blank control group and groups treated with EM and free Cur.

The apoptosis of $\mathrm{C} 6$ glioma cells induced by Cur and Cur/ MPEG-PLA micelles was determined by FCM using Annexin V-FITC/PI staining. According to Figure 7, in the NS and EM groups, the glioma cell apoptosis rates were 2.48\% and $1.98 \%$. In the free Cur and Cur/MPEG-PLA micelle treatment groups, the cell apoptosis rates were $10.79 \%$ and $15.24 \%$ at the drug concentration of $3.125 \mu \mathrm{g} / \mathrm{mL}$. At the drug concentration of $6.25 \mu \mathrm{g} / \mathrm{mL}$, the cell apoptosis rates were $15.45 \%$ and $18.7 \%$. And at the drug concentration of $12.5 \mu \mathrm{g} / \mathrm{mL}$, the cell apoptosis rates were $20.51 \%$ and $51.22 \%$. It is clear that Cur/MPEG-PLA micelles have more pronounced effects of inducing cell apoptosis compared with free Cur and control groups. 

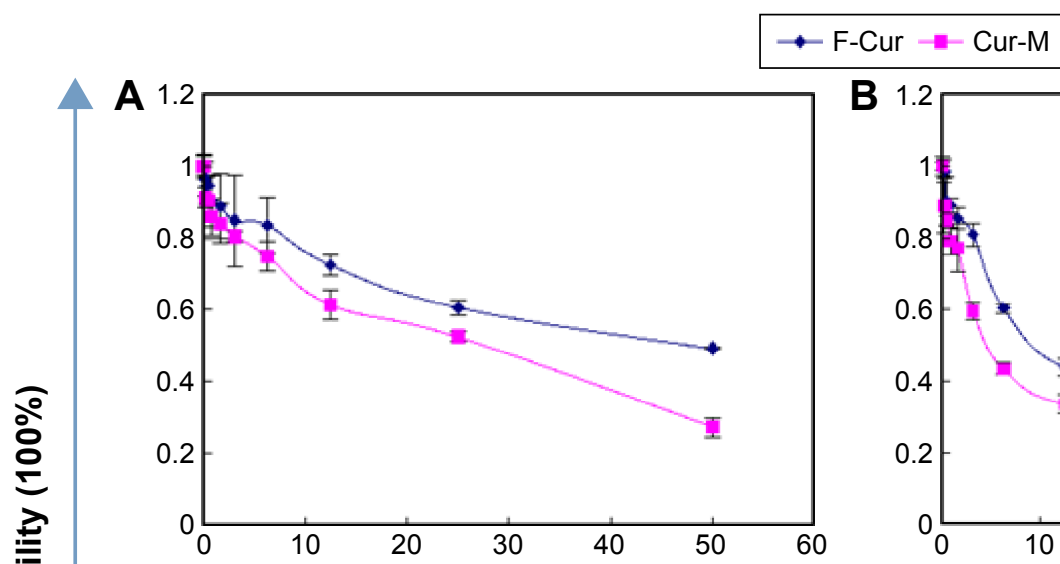

C



B 1.2

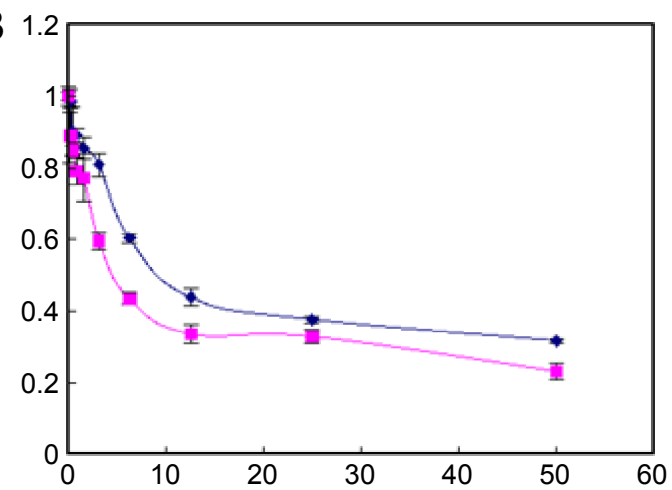

D

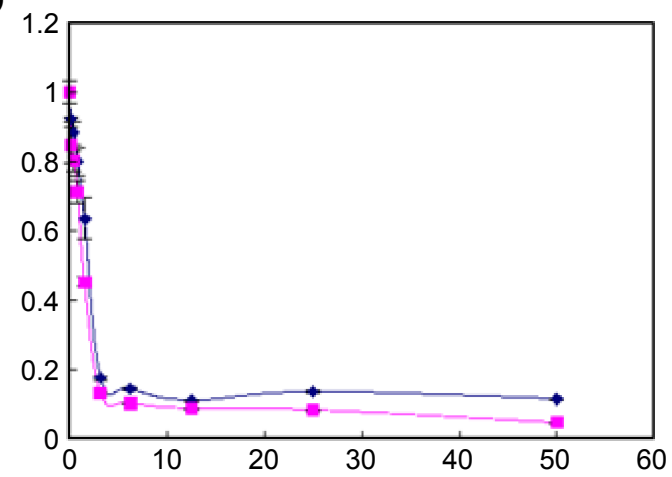

Drug concentration $(\mu \mathrm{g} / \mathrm{mL})$

Figure 4 In vitro cytotoxicity studies of Cur/MPEG-PLA micelles in different glioma cell lines.

Notes: Increasing concentrations of free curcumin and Cur/MPEG-PLA micelles were added to U25I (A and B) and C6 (C and D) glioma cells. After 24 hours (A and C) or 48 hours (B and D) treatment, cells were harvested, and the extent of growth inhibition was measured by MTT assay.

Abbreviations: Cur, curcumin; MPEG-PLA, monomethoxy poly(ethylene glycol)-poly(lactide) copolymer; MTT, 3-(4,5-dimethylthiazol-2-yl)-2,5-diphenyl tetrazolium bromide; F-Cur, free curcumin; Cur-M, Cur/MPEG-PLA micelles.

\section{Nanomicelles improved antiglioma cancer activity of Cur in vivo}

The nude mouse model bearing subcutaneous glioma was applied to evaluate the antiglioma activity of Cur/MPEG-PLA micelles. Four groups of randomly assigned mice bearing

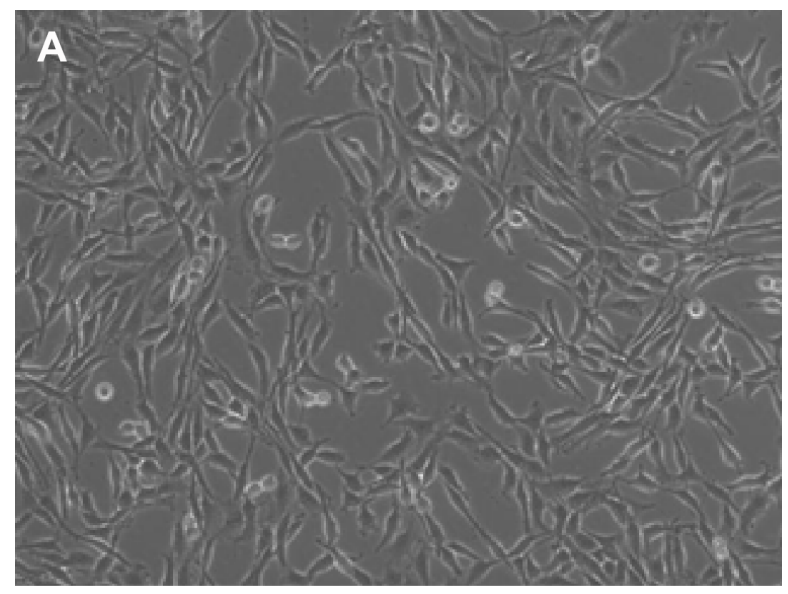

C6 tumor were treated with NS, EM, free Cur, and Cur/MPEGPLA micelles through iv injection, respectively. Results shown in Figure 8 indicate that EM had no antiglioma activity, while free Cur and Cur/MPEG-PLA micelles could inhibit the growth of glioma. And the Cur/MPEG-PLA micelles inhibited glioma

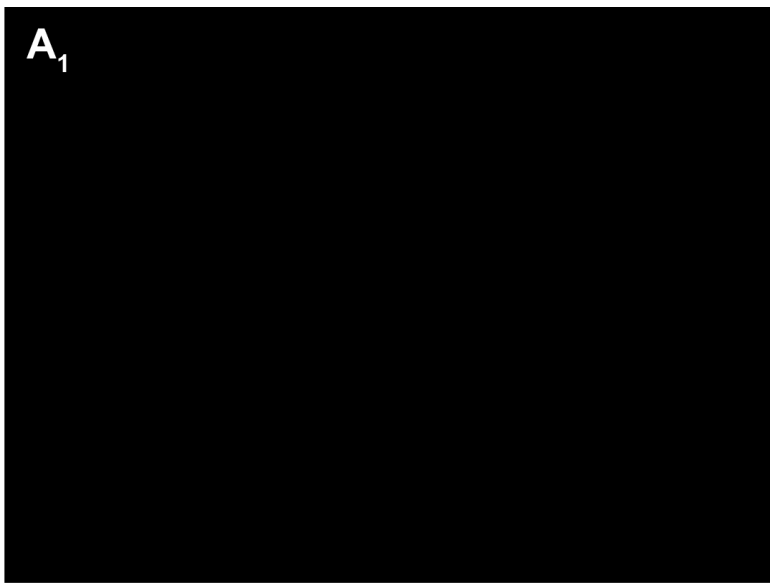

Figure 5 (Continued) 



Figure 5 C6 cell uptake drug assay.

Notes: Fluorescence microphotographs showing C6 cells treated with empty micelles ( $\mathbf{A}$ and $\left.\mathbf{A}_{1}\right)$, free curcumin $\left(\mathbf{B}\right.$ and $\left.\mathbf{B}_{1}\right)$, and Cur/MPEG-PLA micelles $\left(\mathbf{C}\right.$ and $\left.\mathbf{C}_{1}\right)$ at a concentration of $6.4 \mu \mathrm{g} / \mathrm{mL}$ after 4 -hour incubation. Curcumin shows green fluorescence under fluorescence microscopy. $\mathbf{A}-\mathbf{C}$ are bright-filed images and $\mathbf{A}_{1}-\mathbf{C}_{1}$ are fluorescence images.

Abbreviations: Cur, curcumin; MPEG-PLA, monomethoxy poly(ethylene glycol)-poly(lactide) copolymer.
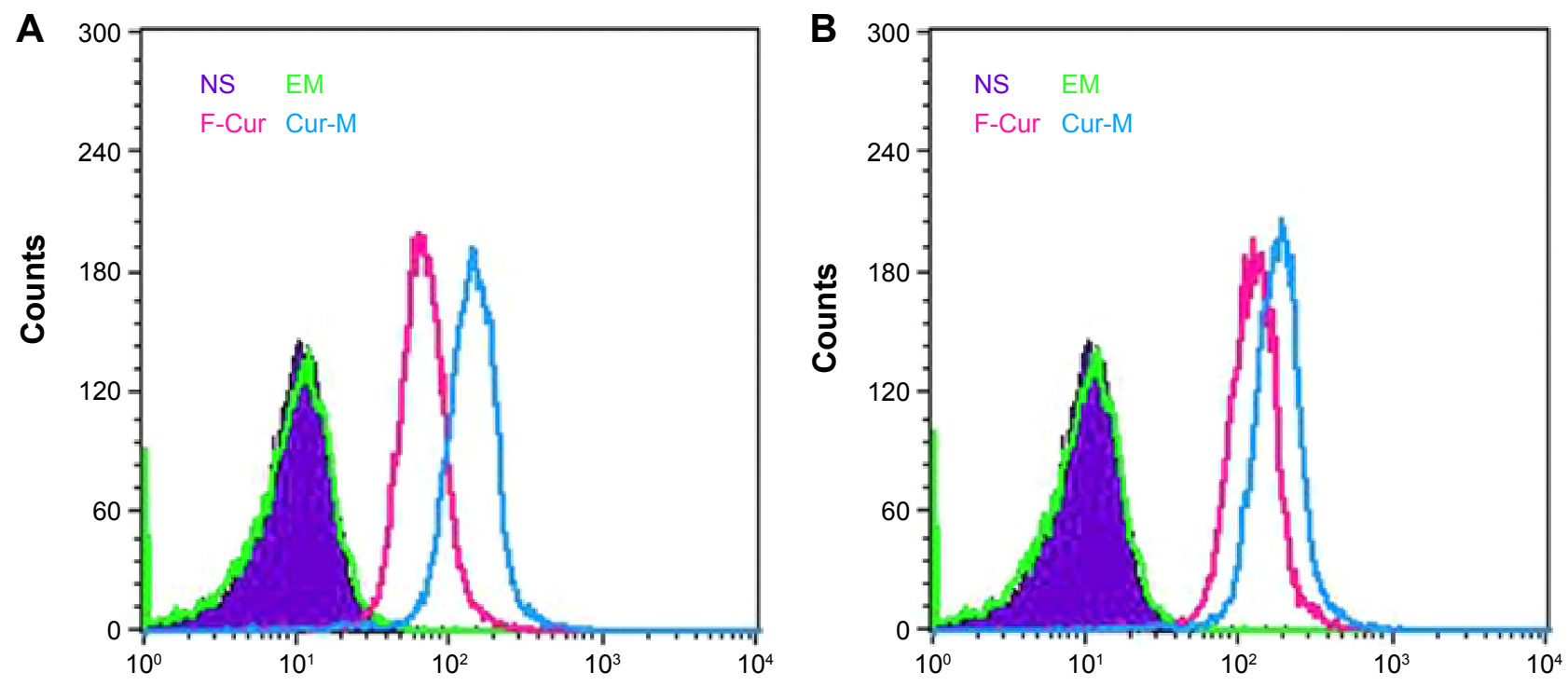

Figure 6 (Continued) 

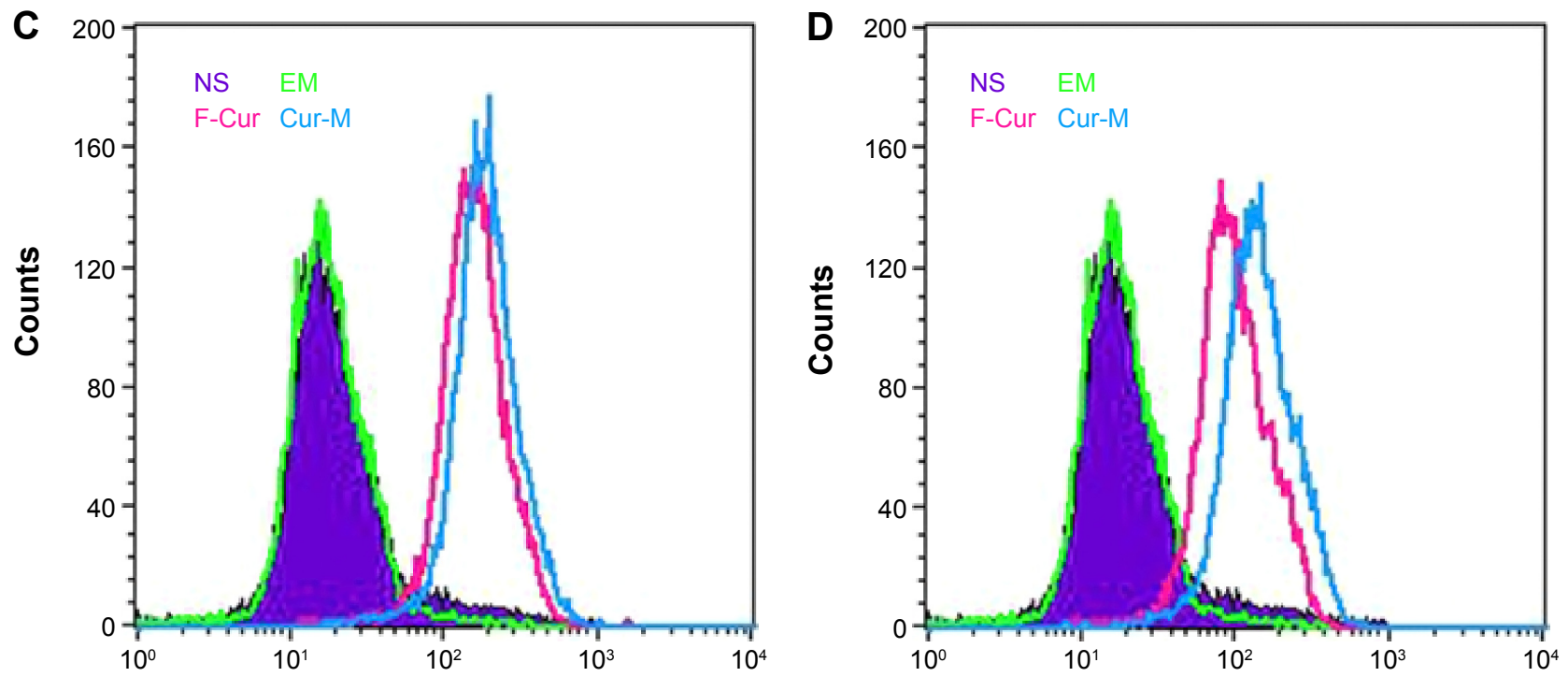

Figure 6 Cell uptake drug assay with FCM.

Notes: FCM histograms showing cellular uptake of curcumin and Cur/MPEG-PLA micelles by C6 (A and B) and U25I (C and D) glioma cells at different drug concentrations after incubation for 4 hours. $3.2 \mu \mathrm{g} / \mathrm{mL}$ (A and C) and $6.4 \mu \mathrm{g} / \mathrm{mL}$ (B and D).

Abbreviations: FCM, flow cytometry; Cur, curcumin; MPEG-PLA, monomethoxy poly(ethylene glycol)-poly(lactide) copolymer; NS, normal saline; EM, empty micelles; F-Cur, free curcumin; Cur-M, Cur/MPEG-PLA micelles.

A

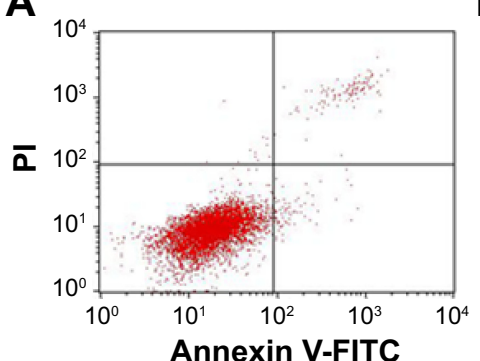

D

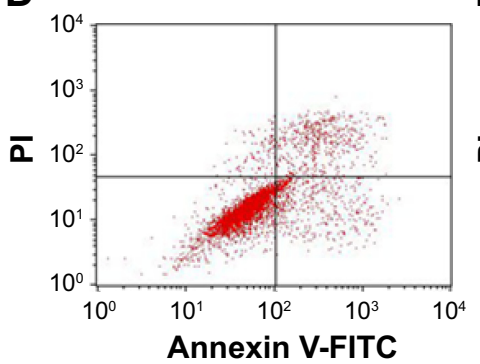

G
B

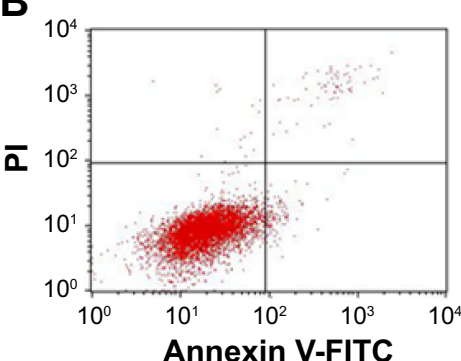

E

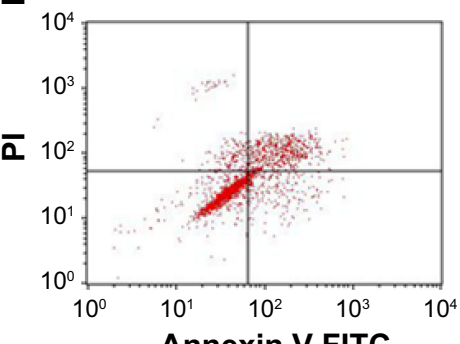

C

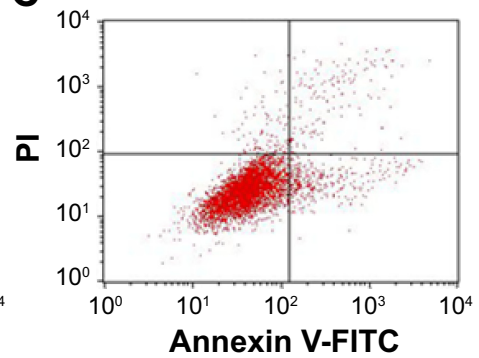

F

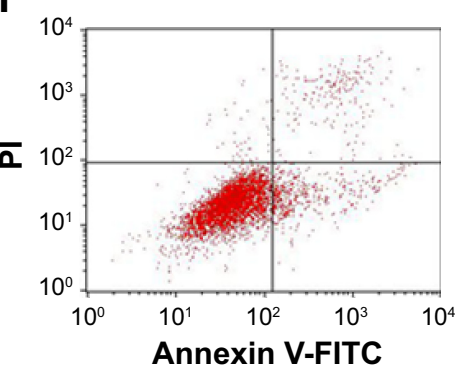

H
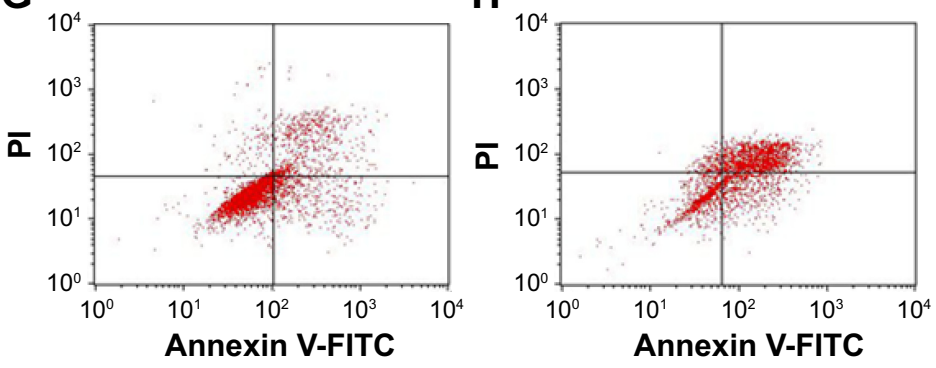

Figure 7 The apoptosis of C6 glioma cells was determined by FCM using Annexin V-FITC/PI staining.

Notes: Normal saline (A), empty micelles (B), free curcumin (C-E), and Cur/MPEG-PLA micelles (F-H) were added to wells at different concentrations, respectively (Cur: $3.125 \mu \mathrm{g} / \mathrm{mL}$ for $\mathbf{C}$ and $\mathbf{F}, 6.25 \mu \mathrm{g} / \mathrm{mL}$ for $\mathbf{D}$ and $\mathbf{G}$, and $12.5 \mu \mathrm{g} / \mathrm{mL}$ for $\mathbf{E}$ and $\mathbf{H}$ ). After incubation for 24 hours, cells were harvested, stained with Annexin V-FITC/ $\mathrm{PI}$, and analyzed with FCM.

Abbreviations: FCM, flow cytometry; FITC, fluorescein isothiocyanate; PI, propidium iodide; Cur, curcumin; MPEG-PLA, monomethoxy poly(ethylene glycol)-poly(lactide) copolymer. 

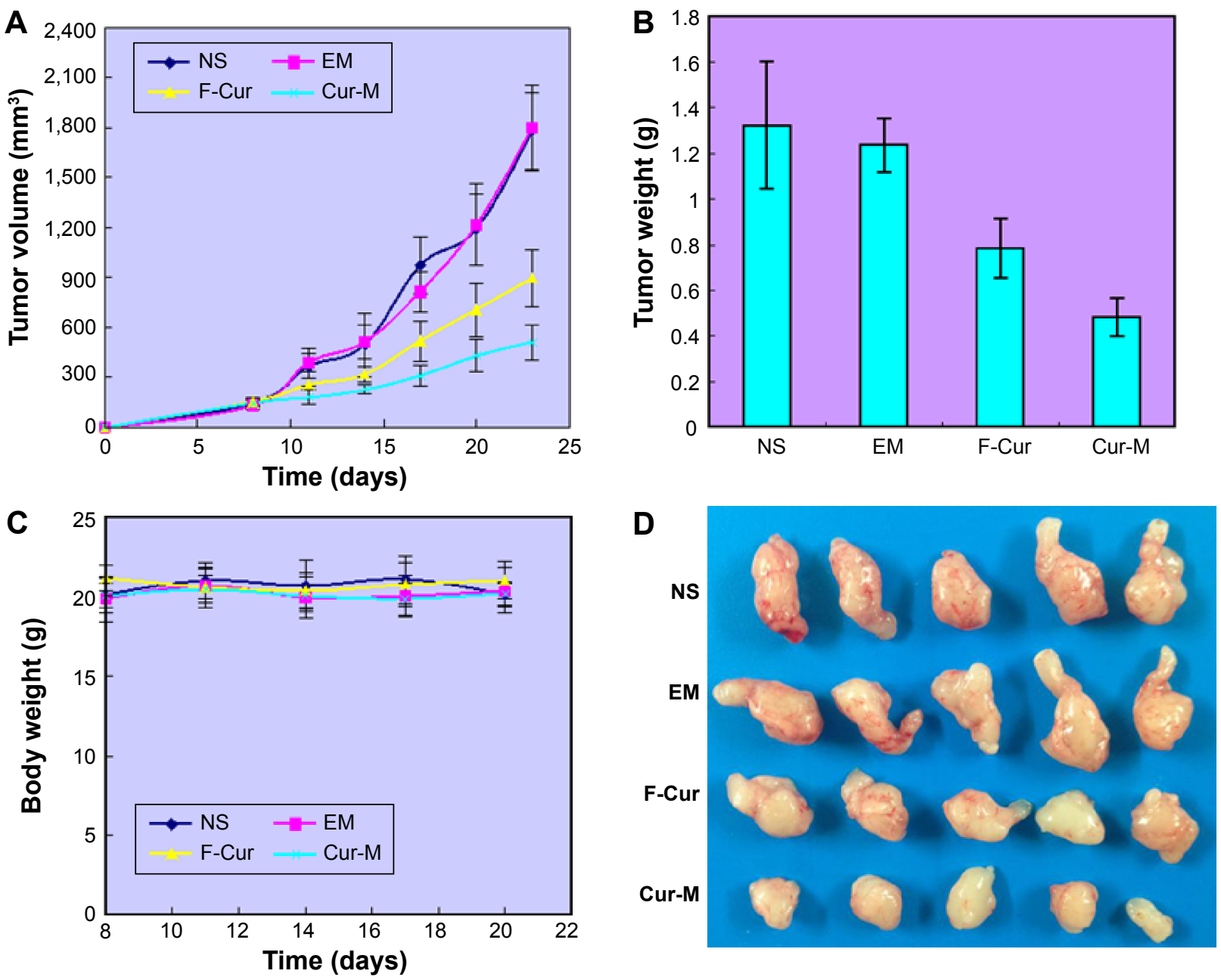

Figure 8 Cur/MPEG-PLA micelles inhibit tumor growth in vivo.

Notes: (A) Suppression of subcutaneous tumor growth by Cur-M in tumor-bearing nude mice and (B) weight of tumors in each treatment group on day 24. (C) Body weight in each treatment group and (D) representative images of subcutaneous tumors in each treatment group.

Abbreviations: Cur, curcumin; MPEG-PLA, monomethoxy poly(ethylene glycol)-poly(lactide) copolymer; Cur-M, Cur/MPEG-PLA micelles; NS, normal saline; EM, empty micelles; F-Cur, free curcumin.

tumor growth more effectively than free Cur. More specifically, the weight of tumor in the Cur/MPEG-PLA micelle group was significantly lower than that in the group treated with free Cur, which suggested that the application of MPEG-PLA micelles enhanced the antiglioma activity of Cur in vivo.

In order to make clear the proliferative activity of glioma, the tumor sections of each group were stained with Ki67. The representative photographs were shown in Figure 9. The Ki67-positive tumor cells significantly reduced in the Cur/MPEG-PLA micelle group compared with that in other groups. The positive cells were counted, and the Ki67 index was significantly lower in the Cur/MPEG-PLA micelle group $(27 \% \pm 3.5 \%)$ than that in groups treated with free Cur (43\% $\pm 5.9 \%)$, EM (67\% $\pm 7.3 \%)$, and NS (70\% $\pm 11.6 \%)$, indicating that Cur/MPEG-PLA micelles could obviously suppress the proliferation of glioma in vivo.
In addition, the TUNEL assay was applied to investigate the mechanism of the improved antiglioma activity of Cur/ MPEG-PLA micelles. As shown in Figure 10, both free Cur and Cur/MPEG-PLA micelles treatment induced significant cellular apoptosis as compared with NS and EM treatment $(P<0.05)$, which was revealed by greenish fluorescence. More apoptosis cells were observed in the Cur/MPEGPLA micelle group than that in the NS, EM, and free Cur groups. The apoptosis index was significantly more in the Cur/MPEG-PLA micelle group $(47 \% \pm 5.5 \%)$ than that in the NS $(3 \% \pm 1.2 \%)$, EM $(2 \% \pm 0.9 \%)$, and free Cur group $(29 \% \pm 3.2 \%)$, which implied that the induction of cellular apoptosis could be a possible approach for Cur/MPEG-PLA micelles to induce antiglioma activity in vivo.

Furthermore, immunofluorescent analysis with antiCD31 monoclonal antibody was performed to observe the 

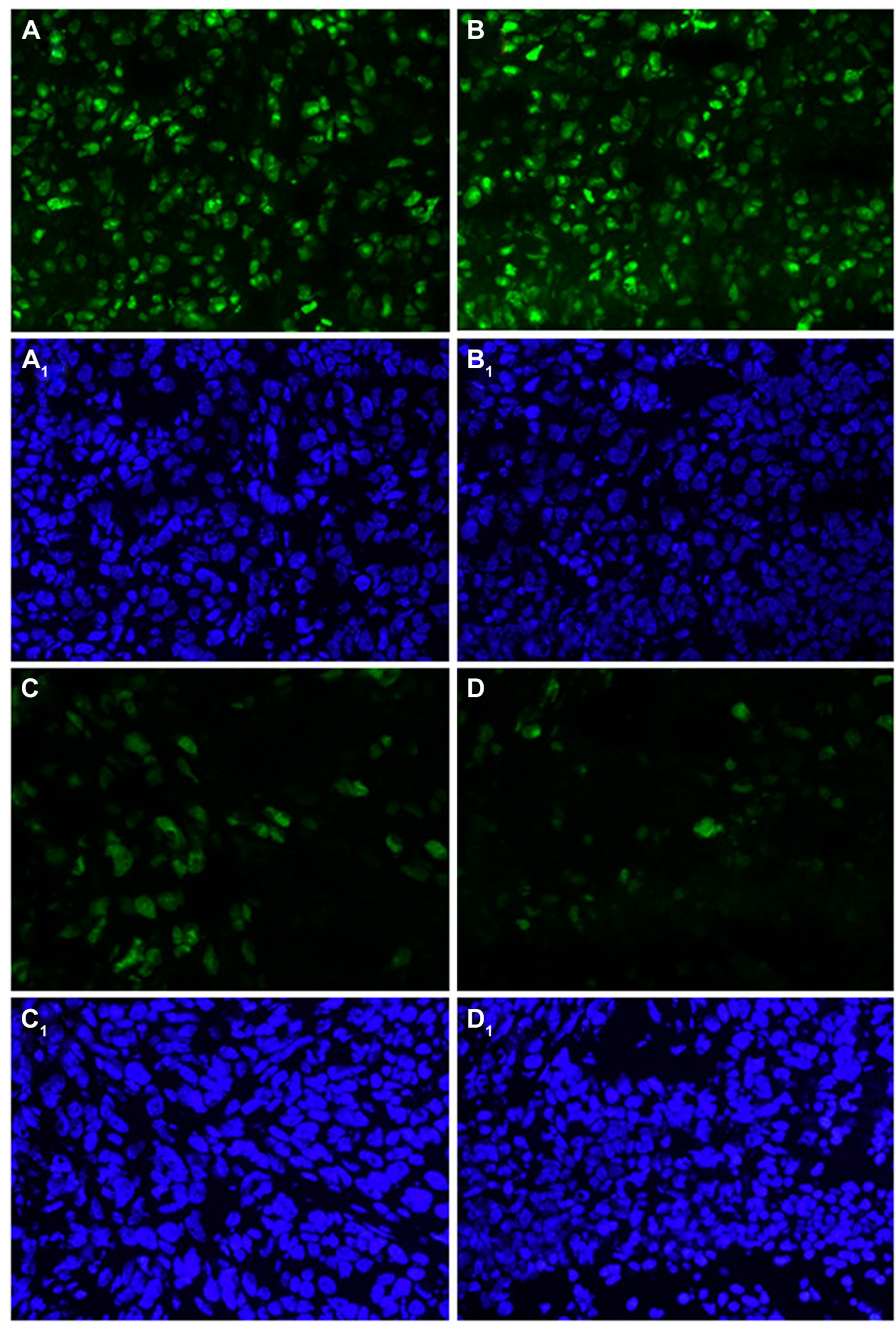

Figure 9 Cell proliferation activity assay with Ki67.

Notes: Ki-67 immunohistochemical staining applied for the assessment of tumor proliferation activity. Each group treated with NS ( $\left.\mathbf{A}_{\text {and }} \mathbf{A}_{1}\right)$, empty micelles $\left(\mathbf{B}_{\text {and }} \mathbf{B}_{1}\right)$, free curcumin ( $\mathbf{C}$ and $\mathbf{C}_{1}$ ), and Cur/MPEG-PLA micelles $\left(\mathbf{D}\right.$ and $\left.\mathbf{D}_{1}\right)$ was stained with Ki-67 antibody $(\mathbf{A}-\mathbf{D})$ and DAPI $\left(\mathbf{A}_{1}-\mathbf{D}_{1}\right)$. Cur/MPEG-PLA micelles showed a pronounced antiproliferative activity compared with that of other groups.

Abbreviations: NS, normal saline; Cur, curcumin; MPEG-PLA, monomethoxy poly(ethylene glycol)-poly(lactide) copolymer; DAPI, 4',6-diamidino-2-phenylindole. 

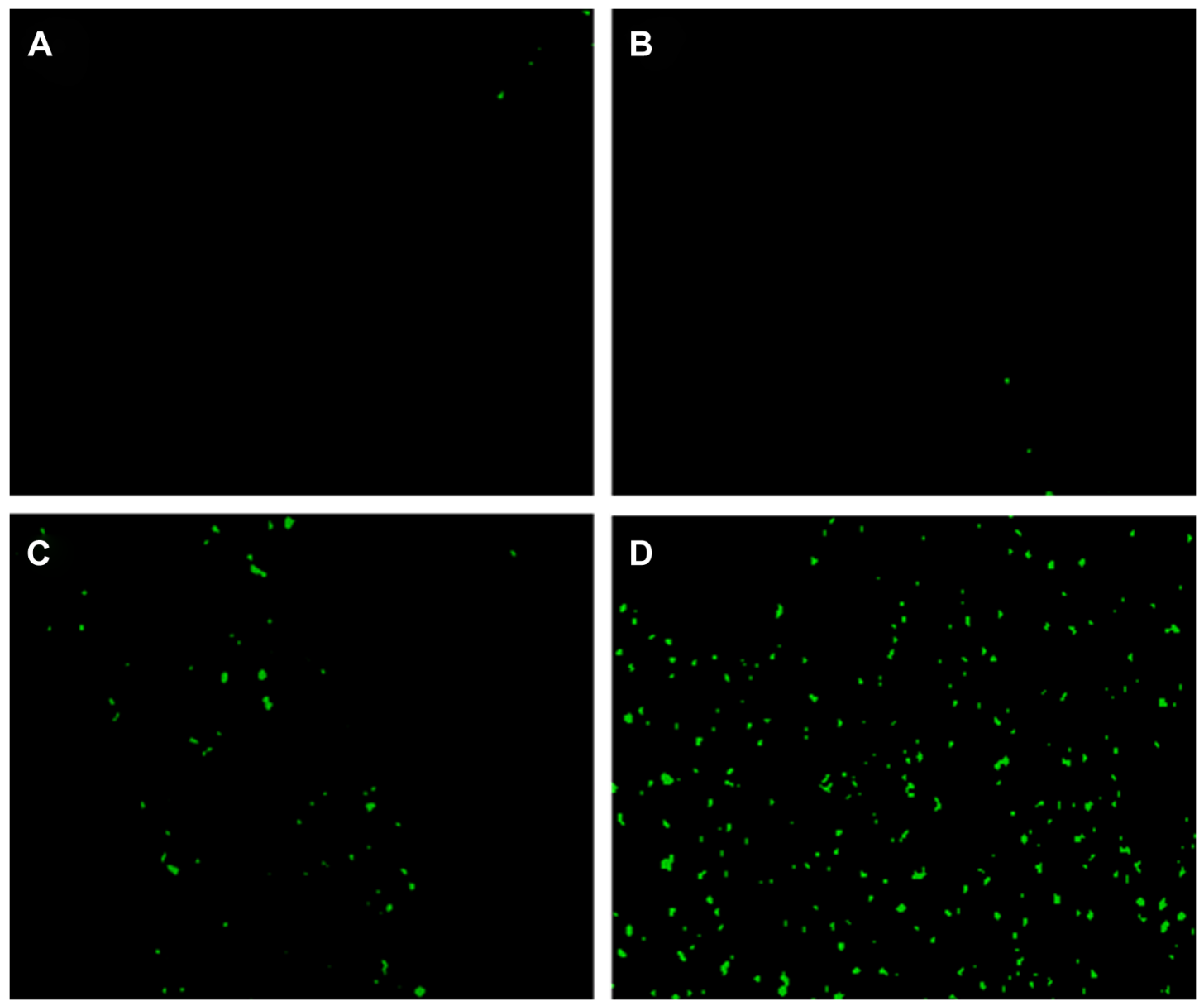

Figure 10 TUNEL test.

Notes: The TUNEL assay was performed for the detection of tumor cell apoptosis in glioma model. Tumor sections of each group treated with NS (A), empty micelles (B), free curcumin (C), and Cur/MPEG-PLA micelles (D) were stained with TUNEL for observation of cell apoptosis. Compared with free curcumin, Cur/MPEG-PLA micelles showed a prominent apoptosis induction effect.

Abbreviations: TUNEL, terminal deoxynucleotidyl transferase-mediated dUTP nick-end labeling; NS, normal saline; Cur, curcumin; MPEG-PLA, monomethoxy poly(ethylene glycol)-poly(lactide) copolymer.

new vasculature content in frozen tumor sections. As shown in Figure 11, CD31-positive endothelial cells in the free Cur treatment group were less than that of the NS group and the empty micelle group but more than that of the Cur/MPEGPLA micelle group (Figure 11A-D). The microvessel number was counted in details. A remarkably fewer of microvessels were present in the free Cur group (31 \pm 7$)$ and the Cur/ MPEG-PLA micelle group (14 \pm 3$)$ compared with the NS

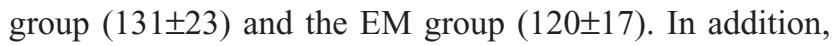
the Cur/MPEG-PLA micelle group reduced the number of microvessels more significantly when compared with the free Cur group $(P<0.05)$. No significant difference was observed between the NS group and the EM group.

\section{Discussions}

Cur has exhibited promising effects for treating cancer in various tissues..$^{8-11,24-27}$ It has received extensive attention with its unique effectiveness in glioma therapy. Previous studies demonstrated that Cur can significantly inhibit the proliferation of glioma cells by downregulating multidrug resistance proteins that cause the efflux of many chemotherapeutic agents. ${ }^{28,29}$ However, its clinical application is severely restricted due to its low water solubility.

In order to resolve the poor aqueous solubility, fast metabolism, and low biological availability of Cur, some materials were used such as liposomes and polymer micelles to improve it. ${ }^{16,30}$ Different aspects should be taken into account when selecting nanodelivery system, including suitable polymer fonts, support stability, chemotherapeutic drug solubility, and so on. As a biodegradable nanometer material, MPEG-PLA micelle has shown promising drug $\mathrm{EE}$, high stability, and low toxicity in drug delivery in previous anticancer research. ${ }^{31-33}$ In this study, we used a biodegradable polymer MPEG-PLA to deliver Cur to the 

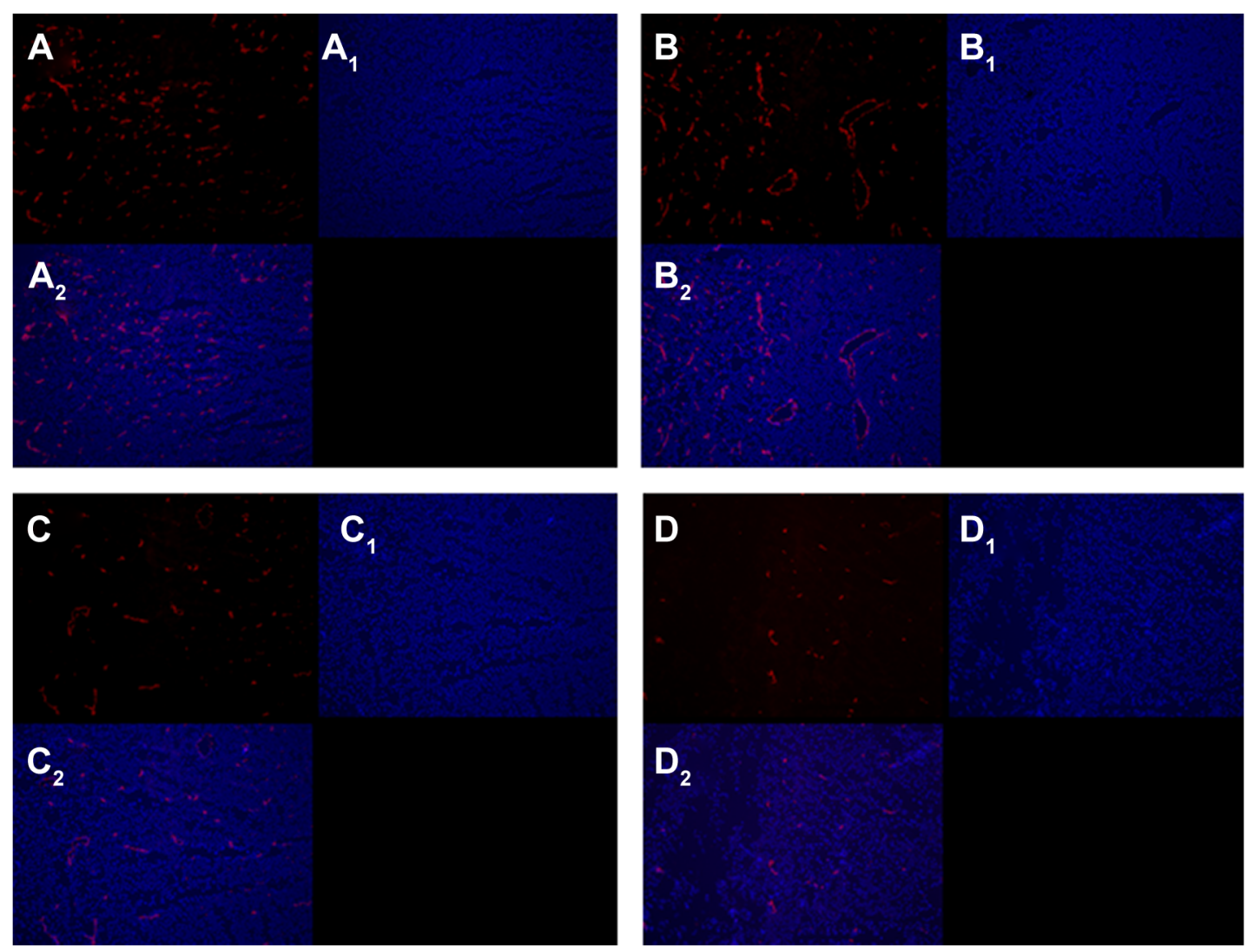

Figure I I Antiangiogenesis analysis with $C D 3$ I immunofluorescence staining.

Notes: Representative CD3I immunofluorescence images for the NS $\left(\mathbf{A}-\mathbf{A}_{2}\right)$, empty micelles $\left(\mathbf{B}-\mathbf{B}_{2}\right)$, free curcumin $\left(\mathbf{C}-\mathbf{C}_{2}\right)$, and Cur/MPEG-PLA micelles $\left(\mathbf{D}-\mathbf{D}_{2}\right)$ are shown. Groups were stained with CD3I antibody $(\mathbf{A}-\mathbf{D})$ and DAPI $\left(\mathbf{A}_{1}-\mathbf{D}_{1}\right)$. Merged images are shown in $\left(\mathbf{A}_{2}-\mathbf{D}_{2}\right)$.

Abbreviations: NS, normal saline; Cur, curcumin; MPEG-PLA, monomethoxy poly(ethylene glycol)-poly(lactide) copolymer; DAPI, 4',6-diamidino-2-phenylindole.

tumor site. Through a one-step solvent evaporation method, Cur was encapsulated into MPEG-PLA micelles to create Cur/MPEG-PLA micelles for better antiglioma effects. Compared with the preparation of Cur Poly (lactic-coglycolide) (PLGA), ${ }^{34}$ the preparation of Cur-MPEG-PLA was very simple and fast.

The Cur/MPEG-PLA assembly model has been demonstrated in Figure 1. Hydrophobic Cur exhibited a high affinity for the domain of PLA locating in the center of the spherical structure, resulting in a high encapsulation efficacy. And the MPEG segments located at the surface of this spherical structure were hydrophilic, which stabilized the Cur/MPEG-PLA micelles in water and prevented the aggregates of nanoparticles. ${ }^{35}$ With these characters, Cur/MPEG-PLA micelles can be fully dispersed in aqueous solution, which is consistent with the appearance of Cur/MPEG-PLA solution and the result of TEM in this study. Furthermore, this core-shell structure may contribute to the sustained drug release in vitro and the high effective treatment of glioma. Compared with the Cur loaded in the PLGA and PEG-PLGA, ${ }^{36,37}$ Cur PLA-PEG nanomicelles have a small particle size, high DL, and high EE.
Although Cur-encapsulated formulations have been made in the recent past, their effectiveness has been limited due to their high particle size and low penetrating capacity into the cancer cells, resulting in poor therapeutic effects in cancer treatment. ${ }^{38-40}$ In a previous study, the gaps between adjacent endothelial cells were $>200 \mathrm{~nm}$. The micelles loading drug with diameter $<200 \mathrm{~nm}$ could pass through the endothelial cell gaps into tumor tissues. ${ }^{41}$ The Cur/MPEG-PLA micelles prepared by our group in this work were monodispersed and showed an average diameter $\sim 33 \pm 2.3 \mathrm{~nm}$ in aqueous phase, which made Cur/MPEG-PLA micelles cross the endothelial cell gaps smoothly so as to improve the antiglioma activity of Cur.

From the pharmacokinetic experiment, we found that the circulation time of Cur nanoformulations in vivo was prolonged, which indicated that the biocompatibility and bioavailability of Cur nanoformulations can be increased, with the same advantages of other Cur formulations. ${ }^{42-45}$ With the encapsulation of MPEG-PLA micelles, Cur was more easily taken up by glioma cells and reached a higher concentration in C6 and U251 cell lines compared with free 
Cur, which was demonstrated in Figures 5 and 6. In this study, since the results of MTT assay showed that the cell viability of C6 and U251 cell lines in the Cur/MPEG-PLA micelle group decreased more significantly, we speculate that the high drug uptake of Cur/MPEG-PLA micelles in glioma cells may contribute much to the enhanced antiglioma activity in vitro. For testing uptake of Cur through FCM, we found that glioma cell features of uptaking of more Cur from Cur nanoparticles was similar to the nanoparticulate Cur made by Mohanty and $\mathrm{Sahoo}^{46}$ and Tripodo. ${ }^{47}$

In the nude mouse model bearing glioma, our study showed that the weights and volumes of subcutaneous gliomas were more effectively inhibited in the Cur/MPEGPLA micelle group compared with other groups. In the meanwhile, the body weights of nude mice in four groups were not statistically significant, indicating a low drug toxicity of Cur/MPEG-PLA micelles to normal tissues. The result of pharmacokinetic study in our research exhibited a more stable plasma concentration of Cur released from Cur/MPEG-PLA micelles, which may be due to the avoidance of elimination of Cur in circulation through encapsulation by MPEG-PLA micelles. Moreover, the sizes of Cur/MPEG-PLA micelles are smaller than the tumor interendothelial junctions. Combined with the impaired lymphatic drainage, the localization of Cur/MPEG-PLA micelles is much improved. As we all know, prolonged accumulation of chemotherapy agents in the tumor region is crucial for effective chemotherapy.

The antitumor mechanisms of Cur were explored in this research. It is known that the nuclear-associated antigen Ki67 is expressed in proliferating cells. Previous studies have shown that Ki67 is closely related to the activity of cell proliferation and could be a predictor of prognosis of various tumors. ${ }^{48,49}$ As shown in Figure 9, the Ki67-positive cells in the Cur treatment groups were much fewer than the control groups, indicating that Cur inhibited glioma through the inhibition of cell proliferation. In addition, tumor sections were stained with CD31 to evaluate the angiogenesis of glioma. The number of microvessels in each group was counted. It was obvious that the Cur treatment led to a marked inhibition of angiogenesis in tumor tissues, which suggested that the mechanism of antiangiogenesis may be involved in the inhibition of glioma by Cur in vivo. Furthermore, the apoptosis tumor cells were also examined in vitro and in vivo. The results of Annexin V-FITC/PI staining in vitro and TUNEL staining of tumor sections were consistent. According to the results shown in Figures 7 and 10, induction of apoptosis may be another mechanism that Cur inhibits glioma. More importantly, the glioma cell apoptosis rate of the Cur/MPEG-PLA micelle group was higher than that of the free Cur group, which implied that MPEG-PLA micelles enhanced the antiglioma activity of Cur.

\section{Conclusion}

Biodegradable Cur/MPEG-PLA micelles were applied to treat glioma cancer in vitro and in vivo. Compared with free Cur, the cellular uptake and cytotoxicity were increased in vitro after Cur was encapsulated into polymeric micelles. Besides, a sustained release behavior was observed in the Cur/MPEG-PLA micelle group in vitro. Furthermore, Cur/ MPEG-PLA micelles showed significant effectiveness on suppressing glioma growth by inducing more cell apoptosis and inhibiting more cell proliferation and angiogenesis versus free Cur. Thus, the Cur/MPEG-PLA micelles in this study may have potential clinical applications in glioma therapy.

\section{Acknowledgment}

This work was supported by the National Natural Science Foundation of China (NSFC81502165) and Sichuan University Outstanding Young Scholars Research Fund (2016SCU04A04).

\section{Disclosure}

The authors report no conflicts of interest in this work. The authors alone are responsible for the content and writing of the paper.

\section{References}

1. Jones $\mathrm{C}, \mathrm{Baker} \mathrm{SJ}$. Unique genetic and epigenetic mechanisms driving paediatric diffuse high-grade glioma. Nat Rev Cancer. 2014;14(10): 651-661.

2. Cuddapah VA, Robel S, Watkins S, Sontheimer H. A neurocentric perspective on glioma invasion. Nat Rev Neurosci. 2014;15(7):455-465.

3. Norden AD, Drappatz J, Wen PY. Antiangiogenic therapies for highgrade glioma. Nat Rev Neurol. 2009;5(11):610-620.

4. Turcan S, Rohle D, Goenka A, et al. IDH1 mutation is sufficient to establish the glioma hypermethylator phenotype. Nature. 2012;483(7390): 479-483.

5. Xi G, Hayes E, Lewis R, et al. CD133 and DNA-PK regulate MDR1 via the PI3K- or Akt-NF-אB pathway in multidrug-resistant glioblastoma cells in vitro. Oncogene. 2016;35(2):241-250.

6. Tan B, Li Y, Zhao Q, et al. Inhibition of Vav3 could reverse the drug resistance of gastric cancer cells by downregulating JNK signaling pathway. Cancer Gene Ther. 2014;21(12):526-531.

7. Stedt H, Samaranayake H, Pikkarainen J, et al. Improved therapeutic effect on malignant glioma with adenoviral suicide gene therapy combined with temozolomide. Gene Ther. 2013;20(12):1165-1171.

8. Milacic V, Banerjee S, Landis-Piwowar KR. Curcumin inhibits the proteasome activity in human colon cancer cells in vitro and in vivo. Cancer Res. 2008;68(18):7283-7292.

9. Aggarwal BB, Shishodia S, Takada Y, et al. Curcumin suppresses the paclitaxel-induced nuclear factor-kappaB pathway in breast cancer cells and inhibits lung metastasis of human breast cancer in nude mice. Clin Cancer Res. 2005;11(20):7490-7498.

10. Dhillon N, Aggarwal BB, Newman RA, et al. Phase II trial of curcumin in patients with advanced pancreatic cancer. Clin Cancer Res. 2008; 14(14):4491-4499. 
11. Kunnumakkara AB, Guha S, Krishnan S, Diagaradjane P, Gelovani J, Aggarwal BB. Curcumin potentiates antitumor activity of gemcitabine in an orthotopic model of pancreatic cancer through suppression of proliferation, angiogenesis, and inhibition of nuclear factor-kappaBregulated gene products. Cancer Res. 2007;67(8):3853-3861.

12. Zanotto-Filho A, Braganhol E, Schröder R, et al. NF $\kappa B$ inhibitors induce cell death in glioblastomas. Biochem Pharmacol. 2011;81(3): 412-424.

13. Zanotto-Filho A, Braganhol E, Edelweiss MI, et al. The curry spice curcumin selectively inhibits cancer cells growth in vitro and in preclinical model of glioblastoma. J Nutr Biochem. 2012;23(6):591-601.

14. Malam Y, Loizidou M, Seifalian AM. Liposomes and nanoparticles: nanosized vehicles for drug delivery in cancer. Trends Pharmacol Sci. 2009;30(11):592-599.

15. Singh S, Dash AK. Paclitaxel in cancer treatment: perspectives and prospects of its delivery challenges. Crit Rev Ther Drug Carrier Syst. 2009;26(4):333-372.

16. Nurunnabi M, Cho KJ, Choi JS, Huh KM, Lee YK. Targeted near-IR QDs-loaded micelles for cancer therapy and imaging. Biomaterials. 2010;31(20):5436-5444.

17. Kim BY, Rutka JT, Chan WC. Nanomedicine. N Engl J Med. 2010; 363(25):2434-2443.

18. Misra R, Acharya S, Sahoo SK. Cancer nanotechnology: application of nanotechnology in cancer therapy. Drug Discov Today. 2010; 15(19-20):842-850.

19. Gong C, Wang C, Wang Y, et al. Efficient inhibition of colorectal peritoneal carcinomatosis by drug loaded micelles in thermosensitive hydrogel composites. Nanoscale. 2012;4(10):3095-3104.

20. Fang J, Nakamura H, Maeda H. The EPR effect: unique features of tumor blood vessels for drug delivery, factors involved, and limitations and augmentation of the effect. Adv Drug Deliv Rev. 2011;63(3): 136-151.

21. Maeda H. Tumor-selective delivery of macromolecular drugs via the EPR effect: background and future prospects. Bioconjug Chem. 2010 21(5):797-802.

22. Gao X, Wang B, Wei X, et al. Anticancer effect and mechanism of polymer micelle-encapsulated quercetin on ovarian cancer. Nanoscale. 2012;4(22):7021-7030.

23. Gao X, Zheng FJ, Guo G, et al. Improving the anti-colon cancer activity of curcumin with biodegradable nano-micelles. J Mater Chem B. 2013;1:5778-5790.

24. Poole KM, Nelson CE, Joshi RV, et al. ROS-responsive microspheres for on demand antioxidant therapy in a model of diabetic peripheral arterial disease. Biomaterials. 2015;41:166-175.

25. He GL, Liu Y, Li M, et al. The amelioration of phagocytic ability in microglial cells by curcumin through the inhibition of EMF-induced pro-inflammatory responses. $J$ Neuroinflammation. 2014;11:49.

26. Koeberle A, Muñoz E, Appendino GB, et al. SAR studies on curcumin's pro-inflammatory targets: discovery of prenylated pyrazolocurcuminoids as potent and selective novel inhibitors of 5-lipoxygenase. $J \mathrm{Med}$ Chem. 2014;57(13):5638-5648.

27. Palange AL, Di Mascolo D, Carallo C, Gnasso A, Decuzzi P. Lipidpolymer nanoparticles encapsulating curcumin for modulating the vascular deposition of breast cancer cells. Nanomedicine. 2014;10(5): 991-1002.

28. Yang HW, Lu YJ, Lin KJ, et al. EGRF conjugated PEGylated nanographene oxide for targeted chemotherapy and photothermal therapy. Biomaterials. 2013;34(29):7204-7214.

29. Chearwae W, Wu CP, Chu HY, Lee TR, Ambudkar SV, Limtrakul P. Curcuminoids purified from turmeric powder modulate the function of human multidrug resistance protein 1 (ABCC1). Cancer Chemother Pharmacol. 2006;57(3):376-388.

30. Wang J, Wang H, Zhu R, Liu Q, Fei J, Wang S. Anti-inflammatory activity of curcumin-loaded solid lipid nanoparticles in IL-1 $\beta$ transgenic mice subjected to the lipopolysaccharide-induced sepsis. Biomaterials. 2015;53:475-483.
31. Wang $\mathrm{H}, \mathrm{Zhao} \mathrm{Y}, \mathrm{Wu} \mathrm{Y}$, et al. Enhanced anti-tumor efficacy by co-delivery of doxorubicin and paclitaxel with amphiphilic methoxy PEG-PLGA copolymer nanoparticles. Biomaterials. 2011;32(32):8281-8290.

32. Sharma G, Park J, Sharma AR, et al. Methoxy poly(ethylene glycol)poly(lactide) nanoparticles encapsulating quercetin act as an effective anticancer agent by inducing apoptosis in breast cancer. Pharm Res. 2015;32(2):723-735.

33. Xu W, Ling P, Zhang T. Toward immunosuppressive effects on liver transplantation in rat model: tacrolimus loaded poly(ethylene glycol)poly(D,L-lactide) nanoparticle with longer survival time. Int J Pharm. 2014;460(1-2):173-180.

34. Yallapu MM, Gupta BK, Jaggi M, Chauhan SC. Fabrication of curcumin encapsulated PLGA nanoparticles for improved therapeutic effects in metastatic cancer cells. J Colloid Interface Sci. 2010;351:19-29.

35. Wang Y, Wang C, Fu S, et al. Preparation of tacrolimus loaded micelles based on poly( $\varepsilon$-caprolactone)-poly(ethylene glycol)-poly( $\varepsilon$ caprolactone). Int J Pharm. 2011;407(1-2):184-189.

36. Najeh MK, do Nascimento TC, Casa DM, et al. Pharmacokinetics of curcumin-loaded PLGA and PLGA-PEG blend nanoparticles after oral administration in rats. Colloids Surf B Biointerfaces. 2013; 101:353-360.

37. Deepti C, Lipika R, Ashish D, et al. Photoprotective efficiency of PLGAcurcumin nanoparticles versus curcumin through the involvement of ERK/AKT pathway under ambient UV-R exposure in $\mathrm{HaCaT}$ cell line. Biomaterials. 2016;84:25-41.

38. Naksuriya O, Okonogi S, Schiffelers RM, Hennink WE. Curcumin nanoformulations: a review of pharmaceutical properties and preclinical studies and clinical data related to cancer treatment. Biomaterials. 2014;35(10):3365-3383.

39. Yallapu MM, Khan S, Maher DM, et al. Anti-cancer activity of curcumin loaded nanoparticles in prostate cancer. Biomaterials. 2014;35(30): 8635-8648.

40. Taurin S, Nehoff H, Diong J, Larsen L, Rosengren RJ, Greish K. Curcumin-derivative nanomicelles for the treatment of triple negative breast cancer. J Drug Target. 2013;21(7):675-683.

41. Wang X, Yang L, Chen ZG, Shin DM. Application of nanotechnology in cancer therapy and imaging. CA Cancer J Clin. 2008;58(2):97-110.

42. Gao Y, Li Z, Sun M, et al. Preparation, characterization, pharmacokinetics, and tissue distribution of curcumin nanosuspension with TPGS as stabilizer. Drug Dev Ind Pharm. 2010;36(10):1225-1234.

43. Tripodo G, Pasut G, Trapani A, et al. Inulin-D-alpha-tocopherol succinate (INVITE) nanomicelles as a platform for effective intravenous administration of curcumin. Biomacromolecules. 2015;16(2):550-557.

44. Sun J, Bi C, Chan HM, Sun S, Zhang Q, Zheng Y. Curcumin-loaded solid lipid nanoparticles have prolonged in vitro antitumour activity, cellular uptake and improved in vivo bioavailability. Colloids Surf B Biointerfaces. 2013;111:367-375.

45. Zou P, Helson L, Maitra A, Stern ST, McNeil SE. Polymeric curcumin nanoparticle pharmacokinetics and metabolism in bile duct cannulated rats. Mol Pharm. 2013;10(5):1977-1987.

46. Mohanty C, Sahoo SK. The in vitro stability and in vivo pharmacokinetics of curcumin prepared as an aqueous nanoparticulate formulation. Biomaterials. 2010;31(25):6597-6611.

47. Tripodo G, Chlapanidas T, Perteghella S, et al. Mesenchymal stromal cells loading curcumin-INVITE-micelles: a drug delivery system for neurodegenerative diseases. Colloids Surf B Biointerfaces. 2015; 125(0):300-308.

48. Miconi G, Palumbo P, Dehcordi SR, et al. Immunophenotypic characterization of human glioblastoma stem cells: correlation with clinical outcome. J Cell Biochem. 2015;116(5):864-876.

49. Laurinavicius A, Green AR, Laurinaviciene A, et al. Ki67/SATB1 ratio is an independent prognostic factor of overall survival in patients with early hormone receptor-positive invasive ductal breast carcinoma. Oncotarget. 2015;6(38):41134-41145. 


\section{Publish your work in this journal}

The International Journal of Nanomedicine is an international, peerreviewed journal focusing on the application of nanotechnology in diagnostics, therapeutics, and drug delivery systems throughout the biomedical field. This journal is indexed on PubMed Central, MedLine, CAS, SciSearch $\AA$, Current Contents $\AA /$ Clinical Medicine,
Journal Citation Reports/Science Edition, EMBase, Scopus and the Elsevier Bibliographic databases. The manuscript management system is completely online and includes a very quick and fair peer-review system, which is all easy to use. Visit http://www.dovepress.com/ testimonials.php to read real quotes from published authors.

Submit your manuscript here: http://www.dovepress.com/international-journal-of-nanomedicine-journal 